\title{
EFFECTS OF UNILATERAL INTRAVITREAL BEVACIZUMAB ON THE CONTRALATERAL EYE HAVING DIABETIC MACULAR EDEMA
}

\author{
Aziz Jan Bashir, Abdul Hannan, Salman Sohail Chaudhary, Sarah Zafar, Abdullah Naeem Syed, Syed Hassan Massana \\ Al-Shifa Trust Eye Hospital, Rawalpindi Pakistan
}

\begin{abstract}
Objective: To investigate the effect of unilateral intravitreal Bevacizumab on contralateral eye in bilateral diabetic macular edema.

Study Design: Quasi-experimental study.

Place and Duration of Study: Retina Department of Al-Shifa Trust Eye Hospital, Rawalpindi, from Sep to Dec 2020.

Methodology: Thirty-two patients were enrolled with consecutive sampling. All the patients had clinically diagnosed diabetic macular edema having $>275 \mu \mathrm{m}$ macular thickness on OCT. They were injected with $1.25 \mathrm{mg} / 0.05 \mathrm{~mL}$ of Bevacizumab in one eye. Baseline macular thickness was compared with 4 weeks follow up macular thickness, using Optical Coherence Tomography.

Results: The central macular thickness in the untreated eye at baseline was $396.97 \pm 29.79 \mu \mathrm{m}$ and $388.34 \pm 30.06 \mu \mathrm{m}$ at 4 weeks $(p$-value $=0.001)$. The difference in central macular thickness in treated and untreated eyes were $28.44 \pm 4.11 \mu \mathrm{m}$ and $19.81 \pm 5.31 \mu \mathrm{m}$ respectively $(p$-value $=0.001)$. There were statistically significant differences between these measurements.

Conclusion: Injecting Bevacizumab in one eye for diabetic macular edema has statistically significant effect on the contralateral non-injected eye macular thickness.
\end{abstract}

Keywords: Bevacizumab, Central retinal thickness, Diabetic macular edema, Intravitreal injection.

How to Cite This Article: Bashir AJ, Hannan AS, Chaudhary SS, Zafar S, Syed AN, Massana SH. Effects of Unilateral Intravitreal Bevacizumab on the Contralateral Eye Having Diabetic Macular Edema. Pak Armed Forces Med J 2021; 71(6): 2075-2077. Doi: https://doi.org/10.51253/pafmj.v6i6.5853

This is an Open Access article distributed under the terms of the Creative Commons Attribution License (https://creativecommons.org/licenses/by-nc/4.0/), which permits unrestricted use, distribution, and reproduction in any medium, provided the original work is properly cited.

\section{INTRODUCTION}

Intravitreal anti-vascular endothelial growth factors (anti-VEGFs) are an effective option for patients with diabetic macular edema (DME) and age-related macular disease, ${ }^{1}$ which are one of the most common causes of debilitating blindness and poor visual acuity in adults worldwide and in our community.,2,3 Intravitreal Anti VEGFs are also used for a host of other ocular diseases such as retinal vein occlusion related macular edema, wet age related macular degeneration and few vascular ocular tumours. ${ }^{4,5}$

The intravitreal anti VEGF injection most commonly used and that is readily available in Pakistan is injection Bevacizumab that can be costly and Pakistan being a developing country, not all patients are able to get the treatment necessary, for a better vision. Although Bevacizumab is the cheapest of other available options in the local market, but its price is highly dependent on the number of patients sharing the cost of injection and institution subsidizing its cost. Considering the large number of injections needed to a large portion of patients on monthly basis, this soon

Correspondence: Dr Aziz Jan Bashir, House No. 58, Road A, Phase 3, Bahria Townm Rawalpindi Pakistan

Received: 17 Dec 2020; revision received: 12 Mar 2021; accepted: 24 Mar 2021 becomes a non-affordable modality for many patients and institution alike.

Bevacizumab injected in one eye can theoretically be absorbed by the systemic blood circulation via choroidal circulation owing to the compromised blood retinal barrier in diabetic macular edema. ${ }^{6-9}$ This can in turn have an effect on the fellow eye with the same compromised blood retinal barrier along with its systemic side effects.

This topic has been researched a few times in some case reports with conflicting results; we wished to add to this knowledge to help the ophthalmology community. If such a correlation does exist, this study might help us to be able to decrease the treatment cost for the patients and their multiple visits for the fellow eye, by decreasing the intravitreal injection load for the fellow eye.

Our aim was to study the effects of injecting unilateral intravitreal Bevacizumab injection in one eye and study its effect on the contralateral (untreated) eye. Bevacizumab is the most common drug used at our centre, which is one of the largest setup for ophthalmology in Pakistan. This study will also help us review our current treatment plan for patients with bilateral 
diabetic macular edema that frequently present to our centre.

\section{METHODOLOGY}

This was a quasi-experimental study, conducted at the Retina Department of Al Shifa Trust Eye Hospital Rawalpindi, Pakistan from September to 2020 till December 2020.

Inclusion Criteria: Patients having diabetes mellitus type 1 or 2 , bilateral diabetic macular oedema and retinal OCT $>275 \mu \mathrm{m}$ thickness were included.

Exclusion Criteria: Patients having laser done for DME in the past and having macular edema other than that of non-poliferative diabetic retinopathy (NPDR) and poliferative diabetic retinopathy (PDR) related DME were excluded from this study. Bevacizumab injected in the last 3 months in either eye were also excluded. Pregnant or lactating women, patients with history of MI, stroke and TIA, owing to the side effects of anti VEGF were also excluded.

After taking informed consent, $1.25 \mathrm{mg} / 0.05 \mathrm{~mL}$ of Bevacizumab was injected intravitreally in one eye using the Royal College of Ophthalmology guidelines, ${ }^{10}$ in 100 patients having bilateral diabetic macular edema. Primary outcome was to study the injection Bevacizumab effect on the contralateral (untreated) eye, which was defined as any change in OCT, after 1 month. A pre-injection OCT scan of the macula was taken using Heildelberg Systems OCT. One-month post injection OCT scan of the macula was repeated for both eyes, to record any changes in injected vs noninjected eye and compare them.

Data was analysed by using Statistical Package for the social sciences (SPSS) version 23 and MS Excel 2016 software. Mean and SD were calculated for continuous variables. Frequency and percentages were calculated for categorical variables. Independent sample $\mathrm{t}$-test were used to find out the statistical difference. The $p$-value of $\leq 0.05$ was considered significant.

\section{RESULTS}

Thirty two consecutive patients were included in the study. Baseline mean central retinal thickness of treated eyes was $397.84 \pm 31.33 \mu \mathrm{m}$ and mean central retinal thickness after 4 weeks was $369.41 \pm 32.04 \mu \mathrm{m}$. There was statistically significant difference between baseline and 4 weeks mean central retinal thickness of treated eyes $(p$-value $=0.01)$ shown in Table-I.

Baseline mean central retinal thickness of untreated eyes was $396.97 \pm 29.97 \mu \mathrm{m}$ and after 4 weeks was $388.34 \pm 30.06 \mu \mathrm{m}$. There was statistically significant difference between baseline and 4 weeks mean central retinal thickness in untreated eyes $(p$ value $=0.01$ ) shown in Table-II.

Mean central macular thickness difference in injected eyes, was $28.44 \pm 4.11 \mu \mathrm{m}$ and in non-injected eyes was $19.81 \pm 5.3 \mu \mathrm{m} 1(p$-value $=0.01)$ shown in Table-III.

Table-I: Comparison of central retinal thickness of treated eyes.

\begin{tabular}{l|c|c|c} 
& \multicolumn{2}{|c|}{$\begin{array}{c}\boldsymbol{p} \text { - } \\
\text { value }\end{array}$} \\
\cline { 2 - 3 } & Baseline & 4 weeks & \\
Central Retinal & $397.84 \pm$ & $369.41 \pm$ & \multirow{2}{*}{0.001} \\
Thickness of & $31.33 \mu \mathrm{m}$ & $32.04 \mu \mathrm{m}$ & \\
Treated Eyes & & \\
\hline
\end{tabular}

Table-II: Comparison of central retinal thickness of untreated eyes.

\begin{tabular}{l|c|c|c}
\hline & \multicolumn{2}{|c}{$p$} & $\begin{array}{c}p- \\
\text { value }\end{array}$ \\
\cline { 2 - 3 } & Baseline & 4 weeks & \\
Central Retinal & $396.97 \pm$ & $388.34 \pm$ & \multirow{2}{*}{0.001} \\
Thickness of & $29.97 \mu \mathrm{m}$ & $30.06 \mu \mathrm{m}$ & \\
Untreated Eyes & & & \\
\hline
\end{tabular}

Table-III: Mean central retinal thickness difference in injected and non-injected eyes.

\begin{tabular}{l|c|c|c}
\hline & $\begin{array}{c}\text { Injected } \\
\text { Eyes }\end{array}$ & $\begin{array}{c}\text { Non-injected } \\
\text { Eyes }\end{array}$ & $\begin{array}{c}p \text { - } \\
\text { value }\end{array}$ \\
\hline $\begin{array}{l}\text { Central Retinal } \\
\text { Thickness }\end{array}$ & $\begin{array}{c}28.44 \pm 4.11 \\
\mu \mathrm{m}\end{array}$ & $\begin{array}{c}19.81 \pm 5.31 \\
\mu \mathrm{m}\end{array}$ & 0.001 \\
Difference & \multicolumn{2}{|c}{} & \\
\hline
\end{tabular}

\section{DISCUSSION}

This study has shown a statistically significant reduction in central macular thickness in both eyes when injection Bevacizumab was injected in one eye and effect on contralateral eye was observed. Literature review shows contradicting evidence regarding this effect with studies available proving evidence for and against above detected effect.

Such effect was first observed in animal model by the Bakri et al, suggesting the presence of anti VEGF in vitreous of other eye in measurable amounts. ${ }^{11}$ Bakbak et al, also investigated this effect and found significant decrease in contralateral macular thickness. ${ }^{12}$

Plasma levels of anti VEGF following an ocular injection were found in many other studies. Avery et $a l$, found decrease in neovascularization in contralateral eye following injection in other eye, supporting systemic movement of anti VEGF. Decrease in bilateral diabetic and uveitic macular edema was seen in children and adults by other investigators as well. 13,14 Hanhart et al, found considerable cross eye effect in great majority of its test subjects but not all. ${ }^{15}$

On the contrary Velez-Montaya et al, failed to observe any significant decrease in macular edema of 
contralateral eye following injection in a four-week follow-up period. ${ }^{16}$ No effect on contralateral noninjected eye was also found by another investigator but he also mentioned a small sample size and low confidence as the probable cause. ${ }^{17}$

Possible mechanism of anti VEGF absorption from the eye into systemic circulation is suggested in literature. Most probable absorption site is via choroidal circulation, ${ }^{16,18}$ and release of anti VEGF into an untreated eye is via anterior circulation.

The concept being tested in current can help alter and redesign existing protocols for injecting eyes with bilateral disease this helps us take into consideration factors such as endophthalmitis risk, patient comfort and resource management, which would not be considered under current circumstances.

\section{LIMITATION OF STUDY}

The factors like stage of diabetic retinopathy, presence of retinal laser scar, control of diabetes, age, gender, hypertension and renal status, could help us get better study outcomes. Possible comparison of injection Bevacizumab with other anti VEGF such as Ranibizumab and Aflibercept were not made.

\section{CONCLUSION}

Injecting Bevacizumab in one eye for diabetic macular edema has statistically significant effect on the contralateral non-injected eye macular thickness.

\section{Conflict of Interest: None.}

\section{Authors' Contribution}

AJB: Direct contribution, AH: Reviewer, SSC: Data collection, SZ: Data collection, ANS: Data collection, SHM: Data collection.

\section{REFERENCES}

1. Miller K, Fortun JA. Diabetic macular edema: current understanding, pharmacologic treatment options, and developing therapies. Asia Pac J Ophthalmol 2018; 7(1): 28-35.

2. Mumtaz SN, Fahim MF, Arslan M, Shaikh SA, Kazi U, Memon MS. Prevalence of diabetic retinopathy in Pakistan; A systematic review. Pak J Med Sci 2018; 34(2): 493.

3. Flaxman SR, Bourne RR, Resnikoff S, Ackland P, Braithwaite T, Cicinelli MV, et al. Global causes of blindness and distance vision impairment 1990-2020: a systematic review and metaanalysis. Lancet Glob Health. 2017; 5(12): e1221-e1234.

4. Matsuyama K, Ogata N, Matsuoka M, Wada M, Takahashi K, Nishimura T. Plasma levels of vascular endothelial growth factor and pigment epithelium-derived factor before and after intravitreal injection of bevacizumab. Br J Ophthalmol 2010; 94(9): 1215-1218.
5. Zehetner C, Kirchmair R, Huber S, Kralinger MT, Kieselbach GF. Plasma levels of vascular endothelial growth factor before and after intravitreal injection of bevacizumab, ranibizumab and pegaptanib in patients with age-related macular degeneration, and in patients with diabetic macular oedema. Br J Ophthalmol 2013; 97(4): 454-459.

6. Kulikov AN, Sosnovskii SV, Berezin RD, Maltsev DS, Oskanov $\mathrm{DH}$, Gribanov NA. Vitreoretinal interface abnormalities in diabetic macular edema and effectiveness of anti-VEGF therapy: an optical coherence tomography study. Clin Ophthalmol 2017; 11(2): 1995-2002.

7. Chu CJ, Johnston RL, Buscombe C, Sallam AB, Mohamed Q, Yang YC. United Kingdom Pseudophakic Macular Edema Study Group. Risk factors and incidence of macular edema after cataract surgery: a database study of 81984 eyes. Ophthalmol 2016; 123(2): 316-323.

8. Falavarjani KG, Nguyen QD. Adverse events and complications associated with intravitreal injection of anti-VEGF agents: a review of literature. Eye 2013; 27(7): 787-794.

9. Xie J, Ikram MK, Cotch MF, Klein B, Varma R, Shaw JE, et al. Association of diabetic macular edema and proliferative diabetic retinopathy with cardiovascular disease: a systematic review and meta-analysis. JAMA Ophthalmol 2017; 135(6): 586-593.

10. The Royal College of Ophthalmologists (rcophth). Ophthalmic Service Guidance: Intravitreal injection therapy. Available at: https:// www.rcophth.ac.uk/wpcontent/uploads/2018/02/Intravitreal-Injection-TherapyAugust-2018-2.pdf. /2018. (Accessed on December 21,2020)

11. Bakri SJ, Snyder MR, Reid JM, Pulido JS, Singh RJ. Pharmacokinetics of intravitreal bevacizumab (Avastin). Ophthalmol 2007; 114(5): 855-859.

12. Bakbak B, Ozturk BT, Gonul S, Gedik S. The effect of intravitreal bevacizumab and ranibizumab on macular edema of the contralateral eye: A comparative study of two anti-VEGFs. Oman J Ophthalmol 2016; 9(1): 44.

13. Chu CJ, Johnston RL, Buscombe C, Sallam AB, Mohamed Q, Yang YC. United Kingdom pseudophakic macular edema study group. risk factors and incidence of macular edema after cataract surgery: a database study of 81984 eyes. Ophthalmol 2016; 123(2): 316-323.

14. Al-Dhibi H, Khan AO. Bilateral response following unilateral intravitreal bevacizumab injection in a child with uveitic cystoid macular edema. J Pediatr Ophthalmol Strabismus 2009; 13(4): 400-402.

15. Hanhart J, Tiosano L, Averbukh E, Banin E, Hemo I, Chowers I. Fellow eye effect of unilateral intravitreal bevacizumab injection in eyes with diabetic macular edema. Eye 2014; 28(6): 646-653.

16. Avery RL, Castellarin AA, Steinle NC, Dhoot DS, Pieramici DJ, See R, et al. Systemic pharmacokinetics and pharmacodynamics of intravitreal aflibercept, bevacizumab, and ranibizumab. Retina 2017; 37(10): 1847.

17. Velez-Montoya R, Fromow-Guerra J, Burgos O, Landers MB, Morales-Caton V. The effect of unilateral intravitreal bevacizumab (avastin), in the treatment of diffuse bilateral diabetic macular edema: a pilot study. Retina 2009; 29(1): 20-26.

18. Acharya NR, Sittivarakul W, Qian Y, Hong KC, Lee SM. Bilateral effect of unilateral ranibizumab in patients with uveitis-related macular edema. Retina 2011; 31(9): 1871-1876. 